\title{
Development of Korean Rome III Questionnaire: What Will We Do With Korean Rome III Questionnaire?
}

\author{
Yu Kyung Cho
}

Department of Internal Medicine, The Catholic University of Korea, Seoul, Korea

\author{
Article: Development and validation of the Korean Rome III questonnaire for diagnosis of functional gastrointestinal \\ disorders \\ Song $\mathrm{KH}$, Jung $\mathrm{HK}$, Min $\mathrm{BH}$, et al. \\ (J Neurogastroenterol Motil 2013;19:509-515)
}

Functional gastrointestinal disorders (FGIDs) are common in clinical practice and in communities around the world, including Korea. In 2006, definitions and classifications of FGIDs were revised in Rome III. The major points of the Rome III include: (1) changes in the time frame for diagnosis of FGIDs from 12 months to 6 months for the onset, and from 6 months to 3 months for the activity of the symptoms; (2) changes in functional dyspepsia (FD) to postprandial distress and epigastric pain syndromes (PDS and EPS), focusing on FD symptoms with four major symptoms such as bothersome postprandial fullness, early satiation, epigastric pain and epigastric burning; (3) more restrictive criteria for functional disorders of the gallbladder and sphincter of Oddi; and (4) revision in subtyping irritable bowel syndrome (IBS) from an unclear definition to a definition using stool consistency. ${ }^{1,2}$ Overlapping of FGIDs or subtypes is permitted in Rome III, therefore, Rome III criteria provide a less restrictive framework for symptom-based diagnosis.
A validated questionnaire relating to the diagnosis of FGIDs is crucial to assess the prevalence of FGIDs in epidemiologic studies or enroll patients in clinical trials. A simple translation of a published questionnaire usually fails to contain the original meaning because of language and cultural differences. ${ }^{3}$ Therefore, a systematic translation and the cross-cultural adaptation process are essential for research using questionnaires. Cross-cultural translation involves adaptation of the translation to the language and culture of the population in which the questionnaire will be used. It is important since comparative studies can only be carried out between different countries and ethnic groups if the translated study instrument is valid cross culturally. ${ }^{4}$ Systemic translation and independent back translation are essential for accurate translation of the original source. Rome III questionnaire was translated into several languages. ${ }^{2,4}$

In the issue of this journal, Song et $\mathrm{al}^{5}$ nicely reported the Korean Rome III questionnaire (Rome III-K) through structural

Received: September 12, 2013 Revised: September 25, 2013 Accepted: September 25, 2013

(c) This is an Open Access article distributed under the terms of the Creative Commons Attribution Non-Commercial License (http://creativecommons. org/licenses/by-nc/3.0) which permits unrestricted non-commercial use, distribution, and reproduction in any medium, provided the original work is properly cited.

*Correspondence: Yu Kyung Cho, MD

Department of Internal Medicine, The Catholic University of Korea, 222, Banpo-daero, Seocho-gu, Seoul St. Mary’s Hospital, Seoul 137-049, Korea

Financial support: None.

Tel: +82-2-2258-6024, Fax: +82-2-2258-2055, E-mail: ykcho@catholic.ac.kr

Conflicts of interest: None. 
translational processes, which is a valid and reliable tool for use in the Korean speaking population and it revealed good test-retest reliability and satisfactory construct validity.

What will we do with validated Rome III-K? The further step is that its application into clinical setting or clinical/epidemiological research. Several epidemiological studies and clinical trials should now be conducted using the first Korean instrument for diagnosing FGIDs. Actually a few studies were already performed with Rome-III Questionnaire in Korea. Among these, Park et $\mathrm{el}^{6}$ showed that Rome III questionnaire was useful in defining the FGID patients into the functional disorders in Korea. In a recent prevalence study on FD in Korea using the Rome III criteria, $13.4 \%$ of community respondents reported dyspepsia. ${ }^{7}$ Of these FD cases, $47 \%$ were classified as PDS, $26 \%$ as EPS, and $27 \%$ as overlap syndrome. ${ }^{7}$ Upper and lower gastrointestinal symptoms commonly overlap and FGIDs are related to psychological disorders. From those 2 studies, the prevalence of EPS is relatively low; the possible explanation is as follows. First, the Rome III criteria for EPS are relatively strict. Also low prevalence of EPS could be influenced by the difficulty in understanding the meanings between heartburn and epigastric burning in Korean language. In addition, overlap FGIDs were found to be common by Rome III criteria which may limit its wide application. From this background there is a great need for validation and standardization in FGID research. Although Rome III criteria are primarily used for research standardization, application in clinical studies will require a greater simplicity. ${ }^{8}$

Although the criteria are useful in diagnosing and classifying FGID patients, it is very difficult to diagnose all the syndromes based on the Rome III criteria in clinical basis. In addition, Rome III questionnaire are useful in the presumption that organic diseases have been excluded. However, most important thing is whether it has the validation power to differentiate FGIDs from organic diseases, avoiding the need for investigation of organic diseases. This might prove the real clinical utility of Rome III questionnaire.

In conclusion, cross-culturally translated Rome III-K will be useful in clinical and epidemiologic research. Is it a more accurate way of diagnosing FGIDs, and distinguishing organic diseases compared with old questionnaires. Further investigation is needed.

\section{References}

1. Drossman DA, Corazziari E, Delvaux M, et al. Rome III, the Functional Gastrointestinal Disorders, 3rd eds. McLean, VA: Degnon Associates, Inc., 2006.

2. Nakajima S, Takahashi K, Sato J, et al. Spectra of functional gastrointestinal disorders diagnosed by Rome III integrative questionnaire in a Japanese outpatient office and the impact of overlapping. J Gastroenterol Hepatol 2010;25(suppl 1):S138-S143.

3. Berkanovic E. The effect of inadequate language translation on Hispanics' responses to health surveys. Am J Public Healtk 1980; 70:1273-1276.

4. Lee YY, Waid A, Tan HJ, Chua SB, Whitehead WE. Validity and reliability of the Malay-language translation of the Rome III diagnostic questionnaire for irritable bowel syndrome. J Gastroenterol Hepatol 2012;27:746-750.

5. Song KH, Jung HK, Min BH, et al. Development and validation of the Korean Rome III questonnaire for diagnosis of functional gastrointestinal disorders. J Neurogastroenterol Motil 2013;19:509-515.

6. Park JM, Choi MG, Cho YK, et al. Functional gastrointestinal disorders diagnosed by Rome III questionnaire in Korea. J Neurogastroenterol Motil 2011;17:279-286.

7. Kim ES, Lee BJ, Kim YS, Lee SI, Park H. Validation of Rome III criteria in the diagnosis of functional gastrointestinal disorders in Korean patients. Korean J Neurogastroenterol Motil 2008;14:39-44.

8. Dang J, Ardila-Hani A, Amichai MM, Chua K, Pimentel M. Systematic review of diagnostic criteria for IBS demonstrates poor validity and utilization of Rome III. Neurogastroenterol Motil 2012; 24:853-860. 